\title{
Evolutionary Theories of Aging
}

\author{
1. The Need to Understand the Process of Natural Selection
}

\section{Laurent Keller Michel Genoud}

Institute of Ecology, University of Lausanne, Switzerland

\section{Key Words}

Evolutionary theories of aging - Lifespan - Ants · Mammals $\cdot$ Humans nations proposed by Le Bourg are implausible and reflect a misunderstanding of the process of natural selection.

Copyright () 1999 S. Karger AG, Basel

\begin{abstract}
Background: In a Forum article Le Bourg (1998) criticized recent tests of evolutionary theories of aging and suggested alternative explanations for the long lifespan of ant queens and the positive relationship between body size and lifespan in mammals. Moreover, he attempts to criticize evolutionary theories of aging by showing that explanations other than evolutionary theories of aging probably account for the variation in human lifespan across countries. Objective: Here we show that the arguments of Le Bourg suffer several problems. First, many of the arguments reveal a misunderstanding of the process of natural selection. Second, some of the arguments reflect a lack of knowledge of evolutionary theories of aging (e.g. pre-reproductive mortality is not predicted to influence lifespan of organisms contrary to what is claimed). Finally, his final example on lifespan in humans simply is a straw-man because serious evolutionary biologists are well aware of the importance of confounding variables and would certainly not make the type of conclusion suggested by Le Bourg. Conclusion: Although a critical discussion of evolutionary theories of aging is welcome, we believe that the alternative expla-
\end{abstract}

\begin{tabular}{ll}
\hline KARGER & ( 1999 S. Karger AG, Basel \\
Fax +4161306 1234 & 0304-324X/99/0456-0336\$17.50/0 \\
$\begin{array}{l}\text { E-Mail karger@karger.ch } \\
\text { www.karger.com }\end{array}$ & $\begin{array}{l}\text { Accessible online at: } \\
\text { www.karger.com/journals/ger }\end{array}$
\end{tabular}

In a recent Forum article Le Bourg [1] criticizes recent tests of evolutionary theories of aging made by Keller and Genoud [2]. Although a critical discussion of evolutionary theories of aging is welcome, we believe that the alternative explanations proposed by Le Bourg are implausible and reflect a misunderstanding of the process of natural selection. We discuss the three examples he gives in turn.

The first study discussed by Le Bourg is a comparative analysis of lifespan in solitary and eusocial insects (termites, ants and bees). Evolutionary theories propose that aging evolves as the necessary cost of processes increasing early reproductive success $[3,4]$, or because of weaker selection against late-acting mutations [5]. A prediction of these hypotheses is that the rate of aging should increase and the average lifespan decrease as the rate of extrinsic mortality increases [3-9]. Because termite, bee and ant queens live in colonies that are sheltered and heavily defended against predators evolutionary theories predict that queens of eusocial species should have a higher lifespan than solitary insects. In a comparative study including 148 insect species, we showed [2] that the evolution of eusociality has been associated with a 100-fold increase in

\footnotetext{
Laurent Keller

Institute of Ecology, Bâtiment de Biologie

University of Lausanne

CH-1015 Lausanne (Switzerland)

Tel. +41 2169241 73, Fax +41 2169241 05, E-Mail Laurent.Keller@izea.unil.ch
} 
lifespan. This result provides strong support for evolutionary theories of aging since purely mechanistic hypotheses of senescence propose no association between the rate of extrinsic mortality and lifespan.

As an alternative explanation to the observed pattern, Le Bourg [1] suggested that 'a short lifespan of queens would impede, at the very least the growing of any colony' with the effect that 'it would thus be impossible to observe ants if the queens were loaded with a reduced longevity'. Although it is true that a decrease in queens' lifespan would decrease colony productivity, it is not true that ants could not exist if queens had a lower longevity. For example, a colony of the ant Lasius niger can produce thousands of sexuals before the queen reaches 4 years, yet the maximum longevity of queens is greater than 28 years in this species [10]. The same is true for other social insects where queens typically can produce sexuals during several years [11]. Thus, although it is correct that reproductive success increases with increased lifespan, it is not true that ants could not exist if queens had a lower lifespan. Moreover, everything else being equal, reproductive success of any species of animal should also increase with increased lifespan. Thus, there should be strong selection to increase lifespan in any insect species whether or not it is eusocial. Hence, we are back to the paradox of why solitary insects, or for that matter all sexual organisms age, and again, have to rely on the explanation that aging evolves as the necessary cost of processes increasing early reproductive success $[3,4]$, or because of weaker selection against lateacting mutations [5].

A further finding of our comparative study was that monogyne ants (those with a single queen per colony) have higher lifespan than polygyne (multiple queen) ants [2]. This difference again supports evolutionary theories because polygyne queens suffer higher extrinsic mortality than monogyne queens [12]. This conclusion was also criticized by Le Bourg [1]. In an attempt to provide an alternative explanation, he suggested that 'in polygynous species the death of a queen is assuredly a deplorable event, but not a tragic one, because surviving queens may perpetuate the colony'. Again, this reflects a misunderstanding of the process of natural selection because selection does not act for the 'good of the colony'. Indeed, many studies show that individuals use selfish strategies to promote the transmission of their genes, even when this leads to a significant decrease in colony productivity $[13,14]$. Hence, just as in monogyne species, there is strong selection for queens to live longer in polygyne species, and, again, their lower lifespan can only be understood as a necessary cost of processes increasing early reproductive

Evolutionary Theories of Aging success $[3,4]$, or as the result of the weaker selection against late-acting mutations.

The second example discussed by Le Bourg [1] is the positive association between the size of mammals and their longevity. In a recent comparative study, Ricklefs [15] showed that in mammals and birds a larger body mass is associated with both a higher longevity and a lower extrinsic mortality. Thus, the positive association between size and longevity in mammals is predicted by evolutionary theories of aging because larger animals tend to suffer lower extrinsic mortality than smaller mammals. Le Bourg suggests another explanation, namely that because 'large animals require more time to reach adulthood, they consequently need more time to rear their own offspring' with the effect that 'they need to live fairly long to maintain themselves as a species'. Again, this reasoning reflects several misunderstandings of the theory of natural selection because (i) large animals could still reproduce (and survive) if they had lower lifespan (e.g. African elephants, which live more than 50 years, could probably survive with a, say, two times lower lifespan, since puberty occurs between 8 and 13 years of age [16], and (ii) everything else being equal, there is also strong selection for small mammals to live longer because this would significantly increase their reproductive success. Thus, the question becomes why do small mammals not live longer and, again, this is explained by the fact that the higher extrinsic mortality associated with their smaller size selects for higher early reproduction and leads to weaker selection against late-acting mutations [17].

Finally, Le Bourg [1] attempts to criticize evolutionary theories of aging by showing that alternative explanations are possible in some cases. To make his point he takes an example from humans. Data from the French National Institute of Demography show that "countries with low infant mortality tend to have higher longevities than those with high infant mortality'. Le Bourg states that although 'expectations of the evolutionary theories of aging appear to be fulfilled [...] it may be opposed to such a reasoning that these results are due to the fact that, in rich countries, families can easily control the number of their progeny and that the high longevity in these countries, together with the low infant mortality, reflect their high economic status'. It is surprising that Le Bourg attempts to criticize evolutionary theories of aging with such a trivial example. Trying to test evolutionary theories of aging by comparing human lifespan across countries when so many confounding variables (e.g. income, customs, access to medical care) are expected to influence both birth and mortality rates is certainly unwise, at best. Finally, it should also be 
noted that the study of an association between longevity and infant mortality does not allow to test the evolutionary theories of aging, because pre-reproductive mortality is not expected to influence lifespan: infant mortality is thus irrelevant [6].

In conclusion, the arguments of Le Bourg [1] suffer from three general problems. First, many of the arguments reveal a lack of understanding of the process of natural selection. For example, selection does not act for the good of species or colonies. Also, Le Bourg fails to give an explanation for why solitary insects or small mammals do not live longer, although this would greatly increase their reproductive success if there was no trade-off or genetic constraints. Second, some of the arguments, reflect a lack of knowledge of evolutionary theories of aging (e.g. prereproductive mortality is not predicted to influence lifespan of organisms contrary to what is claimed). Third, the final example on lifespan in humans simply is a straw man because serious evolutionary biologists are well aware of confounding variables and would certainly not make the type of conclusion suggested by Le Bourg [1]. This shows that it is necessary to 'handle with care' criticisms of evolutionary theories of aging.

\section{References}

1 Le Bourg E: Evolutionary theories of aging: handle with care. Gerontology 1998;44:345348.

2 Keller L, Genoud M: Extraordinary lifespans in ants: a test of evolutionary theories of ageing. Nature 1997;389:958-960.

3 Williams GC: Pleiotropy, natural selection, and the evolution of senescence. Evolution 1957;11:398-441.

4 Rose M: Evolutionary Biology of Aging. New York, Oxford University Press, 1991.

5 Hamilton WD: The moulding of senescence. $\mathrm{J}$ Theor Biol 1996;12:12-45.

6 Stearns SC: The Evolution of Life-Histories. Oxford, Oxford University Press, 1992.

7 Partridge L, Barton NH: Optimality, mutation and the evolution of ageing. Nature 1993;362: 305-311.
8 Partridge L, Barton NH: On measuring the rate of ageing. Proc R Soc Lond B 1996;263:13651371.

9 Charlesworth B: Evolution in age-structured populations. Cambridge, Cambridge University Press, 1994, 2nd ed.

10 Appel H, Kutter H, Stumper R: Hermann Appel, ein leidgeadelter Entomologe (1892-1966). Proc. VIth Congr IUSSI, Bern, pp 275-279.

11 Hölldobler B, Wilson EO: The Ants. Berlin, Springer, 1990.

12 Nonacs P: Queen number in colonies of social Hymenoptera as a kin-selected adaptation. Evolution 1988;42:566-580.
13 Keller L, Ross KG: Selfish genes: A green beard in the red fire ant. Nature 1998;394:573-575.

14 Keller L, Reeve HK: Dynamics of conflicts within insect societies; in Keller L (ed): Levels of Selection in Evolution. Princeton, Princeton University Press, 1999.

15 Ricklefs RE: Evolutionary theories of aging: Confirmation of a fundamental prediction, with implications for the genetic basis and evolution of life span. Am Nat 1998;152:24-44.

16 Laursen L, Bekoff M: Loxodonta africana. Mammalian Species. Am Soc Mammalogists 1978;92:1-8.

17 Promislov DEL, Harvey PH: Living fast and dying young: A comparative analysis of life-history variation among mammals. J Zool Lond 1990;220:417-437. 